\title{
DIFFERENTIAL EFFECTS OF ESTROGEN AND TESTOSTERONE ON AUDITORY SENSORY GATING IN RATS
}

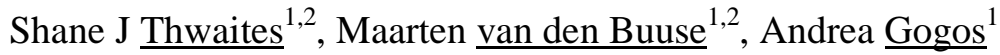 \\ 1) Behavioural Neuroscience Laboratory, Florey Institute of Neuroscience and Mental Health, \\ University of Melbourne, Australia \\ 2) Department of Pharmacology, University of Melbourne, Australia.
}

\section{Communicating Author:}

A/Prof Maarten van den Buuse

Florey Institute of Neuroscience and Mental Health

University of Melbourne

Melbourne, Australia

Email: mvdbuuse@ unimelb.edu.au

Ph: +61 390356624

\section{Acknowledgements:}

All experiments were performed within Australia and comply with current laws. 


\section{ABSTRACT}

Rationale: Estrogen has been shown to have beneficial effects in patients with schizophrenia. However, the mechanisms involved in this protective effect are unclear. Schizophrenia is associated with deficits in sensory gating, a filtering mechanism which normally prevents sensory overload. In rodent models, acute treatment with drugs such as the dopamine D1/D2 receptor agonist, apomorphine, the dopamine releaser, amphetamine, and the glutamate NMDA receptor antagonists, phencyclidine or MK-801, can induce a phenotype similar to that seen in schizophrenia. Objectives: Given the putative protective action of estrogen in schizophrenia, here we investigated the effect of ovariectomy (OVX) and estrogen replacement in female rats on drug-induced auditory gating deficits. For comparison, we also assessed the effects of castration (CAST) and dihydrotestosterone (DHT) replacement in male rats. Methods: Rats were instrumented with cortical surface electrodes. Test sessions comprised of 150 presentations of paired clicks, $500 \mathrm{~ms}$ apart (S1 and S2). Results: Administration of all drugs increased the ratio of responses to S2/S1 in sham-operated female and male rats. OVX reduced ERP amplitudes but did not alter S2/S1 ratio or drug effects. In OVX rats with $17 \beta$-estradiol implants, the effect of apomorphine was abolished but there was no change in that of amphetamine and phencyclidine. There were no effects of CAST or DHT replacement in male rats. Conclusions: Chronic estrogen replacement in OVX rats protected against sensory gating deficits caused by direct dopamine D1/D2 receptor stimulation. These data could indicate a possible mechanism by which estrogen exerts a protective action in schizophrenia.

Keywords: Sensory gating, auditory gating, N40, N1, schizophrenia, estrogen, oestrogen, apomorphine, amphetamine, phencyclidine 


\section{INTRODUCTION}

The 'female' sex steroid, estrogen, has putative neuroprotective and antipsychotic actions in the brain (Chua et al. 2004; Garcia-Segura et al. 2001; Kulkarni et al. 2001; Riecher-Rossler et al. 1994). Compared to males, female schizophrenia patients have a delayed onset of illness, relatively milder symptoms and generally a better overall prognosis (Hafner 2003). Furthermore, female schizophrenia patients have lower estrogen levels than healthy matched controls (Oades and Schepker 1994). However, it is not clear how estrogen may have an antipsychotic effect or how testosterone may be involved in the illness.

Schizophrenia patients have abnormalities of a sensory information processing mechanism known as sensory gating (Adler et al. 1982; Olincy et al. 2010; Patterson et al. 2008). Deficiencies of sensory gating prevent schizophrenia patients from filtering sensory information efficiently, making it difficult for a patient to select and focus on the most important parts of sensory information in the environment (Light and Braff 1999; Venables 1964). Sensory gating deficits in schizophrenia patients are associated with cognitive decline and psychotic symptoms and are resistant to treatment with classical antipsychotic drugs (Becker et al. 2004; Light et al. 2000). Sensory gating has been investigated in a number of different experimental paradigms, such as suppression of the P50 (Patterson et al. 2008), N100 (Boutros et al. 2009) or P200 event-related potentials (ERPs) (Jansen et al. 2010), mismatch negativity (Light et al. 2010) and prepulse inhibition of the acoustic startle response (PPI) (Light and Braff 1999). Previous work in our laboratory has shown that chronic estrogen replacement in ovariectomized rats prevents disruption of PPI by treatment with the dopamine receptor agonist, apomorphine (Gogos et al. 2010) or the serotonin-1A receptor agonist, 8-OH-DPAT (Gogos and Van den Buuse 2004). In contrast, castration of male rats 
reduced the effect of 8-OH-DPAT on PPI and testosterone replacement reversed this effect (Gogos and van den Buuse 2003). With respect to P50 gating, several studies have suggested that normal menstrual cycle fluctuations of sex steroids, including estrogen, do not alter gating ratios (Brenner et al. 2004; Waldo et al. 1987). However, the effect of gonadectomy and chronic treatment with estrogen or testosterone on auditory sensory gating deficits has not been investigated previously.

Suppression of the P50 ERP in the paired-click paradigm can be measured using electroencephalography (EEG). In the paired-click paradigm, two clicks of non-startling white noise are presented to the subject, $500 \mathrm{~ms}$ apart (S1 and S2) (Light et al. 2010). In healthy human subjects the amplitude of the P50 component of the ERP in response to S2 is significantly diminished when compared to the amplitude of S1. However in schizophrenia patients the difference between the response $\mathrm{S} 1$ and $\mathrm{S} 2$ is markedly reduced, indicating that they do not suppress the response to the second sound effectively (Adler et al. 1982; Cadenhead et al. 2005; Olincy et al. 2010). The relevance of this stimulus protocol is that when presented with repetitive information, the brain normally protects the first piece of information, but inhibits the response to the second (repetitive) piece of information (S2). This allows correct processing of information before shifting focus to subsequent information (Light and Braff 1999). Sensory gating in this paradigm is generally expressed as the ratio of the response to the first click and the response to the second click (S2/S1) (Adler et al. 1982; Olincy et al. 2010). An increase of the S2/S1 sensory gating ratio indicates disrupted gating and can occur by either a decrease in the response to S1, or an increase in the response to S2 (Dalecki et al. 2011). In rats, the N1 component of the ERP (also known as N40 or N50) is considered to be analogous to the P50 in human subjects because this component undergoes suppression in the paired-click paradigm (Bickford-Wimer et al. 1990; Boutros et al. 1997; 
Swerdlow et al. 2006). However, some studies have suggested that the rat P1 component is more similar to the human P50 (Keedy et al. 2007). The difference between human and animal studies with regards to latency and polarity of the ERP components is suggested to be due to the differences in the size of head and electrode placement (Bickford-Wimer et al. 1990).

Schizophrenia is associated with increased subcortical dopaminergic activity as well as glutamate NMDA receptor hypofunction (Carlsson et al. 2001). In animal models, psychotomimetic drugs such as the dopamine releaser, amphetamine, the dopamine D1/D2 receptor agonist, apomorphine, and the NMDA receptor antagonists, phencyclidine and MK801 , are used to model psychotic symptoms of schizophrenia. These drugs have been shown to disrupt auditory gating in male rats (Adler et al. 1986; Swerdlow et al. 2006). Using a paired-click auditory gating paradigm, the aims of the present study were therefore to assess the effect of ovariectomy and estrogen replacement on baseline ERP responses and on disruptions of auditory gating caused by apomorphine, amphetamine and NMDA receptor antagonists. For comparison, we also tested male rats, which were either sham-operated, castrated or castrated and replaced with testosterone. Given our previous results with PPI, it was hypothesized that estrogen treatment in ovariectomized rats and castration in male rats would ameliorate the auditory gating deficits caused by these psychoactive drugs. 


\section{METHODS}

\section{Animals}

Female and male Sprague-Dawley rats (Monash Animal Services, Monash University, Victoria, Australia) were housed in groups of 2-3 in standard rat cages. Rats were maintained on a 12-h light/dark cycle (lights on at 7:00 AM) at a constant temperature of $22 \pm 2{ }^{\circ} \mathrm{C}$ and had free access to standard pellet food and water. All surgical techniques, treatments and experimental protocols were in accordance with the Australian Code of Practice for the Care and Use of Animals for Scientific Purposes (1990) set out by the National Health and Medical Research Council of Australia. At the end of their experiments, all rats were killed by pentobarbitone anaesthesia and decapitation. The uterus or seminal vesicles were subsequently dissected out and weighed to verify the effectiveness of ovariectomy or castration, respectively, and hormone replacement.

\section{Surgical procedures: ovariectomy/castration and estrogen treatment}

All rats underwent two discrete surgeries, one week apart. To minimise post-operative pain they were administered $5 \mathrm{mg} / \mathrm{kg}$ of the long-acting non-steroidal anti-inflammatory drug, carprofen (Rimadyl $^{\circledR}$, Pfizer Ltd., Sandwich, Kent, United Kingdom) prior to both surgeries.

At 12 weeks of age, female rats underwent an ovariectomy procedure (OVX) or sham operation (SHAM) (Gogos and Van den Buuse 2004). For ovariectomy surgery, rats were placed on a heat pad in the prone position and anaesthesia was maintained using a $2-3 \%$ mixture of isoflurane (Veterinary Companies of Australia, Artamon, NSW, Australia) and oxygen. Through a $2-3 \mathrm{~cm}$ midline skin incision and $5 \mathrm{~mm}$ flank incisions of the abdominal wall, the ovaries were located and removed bilaterally. The abdominal wall 
incisions were then silk-sutured closed and the skin layer was closed using 2-3 surgical staples. SHAM rats undewent the same surgical procedures as OVX rats except that the ovaries were not removed.

During the ovariectomy procedure all female rats were also instrumented with a subcutaneous silastic implant in the nape of the neck. The previously prepared implants consisted of $11 \mathrm{~mm}$ lengths of silastic tubing (Dow Corning, i.d. 1.98 mm, o.d. 3.18 mm; Futuremedics Australia, Balwyn, VIC, Australia), which were left empty (SHAM and OVX rats) or filled with crystalline 17ß-estradiol (Sigma-Aldrich, St. Louis, MO) (OVX+E rats) and sealed at each end with $3 \mathrm{~mm}$ of silicone sealant. These $17 \beta$-estradiol implants have been shown to produce a serum estradiol concentration of approximately $50 \mathrm{pg} / \mathrm{ml}$, which corresponds to the peak estradiol concentration of the estrous cycle (Albert et al. 1991). Uterus and seminal vesicle weights were used as indirect indicators of whether hormone treatments were successful. SHAM rats were included to allow comparison with the natural condition and estrogen levels in these rats is likely to be variable due to the estrous cycle (Schank 2001).

For castration surgery (Gogos and van den Buuse 2003), male rats were again anesthetized with a 2-3\% isoflurane/oxygen mixture and were placed on a heat pad on their back. A small $(\sim 7 \mathrm{~mm})$ midline incision was created on the scrotum skin and in the muscle layer and the tunica albuginea was located and gently pulled out, removing the testis. Excess adipose tissue was removed and the vas deferens and blood vessels were ligated before being cut. The testis was subsequently removed. The muscle layer was then suture-closed and the process repeated on the contralateral side. The midline incision on the scrotum was also sutureclosed. SHAM rats underwent the same surgical procedures as CAST rats except that the testes were not removed. 
During the castration procedure all rats were implanted with a subcutaneous silastic implant, in the nape of the neck. These implants consisted of $25 \mathrm{~mm}$ lengths of silastic tubing (Dow Corning), which were left empty (SHAM and CAST rats) or filled with the non-aromatizable androgen, dihydrotestosterone (Sigma-Aldrich) (CAST+DHT rats) and sealed at each end with $3 \mathrm{~mm}$ of silicone sealant.

\section{Surgical procedures: Electrode implantation}

One week after ovariectomy surgery, when the rats were 13 weeks old, they were instrumented with electrodes onto the dura mater as previously described by Breier et al. (2010) and Swerdlow et al. (2006). Briefly, rats were anaesthetized with an isoflurane / oxygen mixture and mounted in a stereotaxic apparatus (Stoelting, Wood Dale, IL, USA). Blunt stereotaxic ear bars were used to prevent damage to the tympanic membrane. A $2 \mathrm{~cm}$ midline incision was made and connective tissue was carefully removed from the skull surface. A recording electrode hole was drilled $4 \mathrm{~mm}$ posterior to bregma and $1 \mathrm{~mm}$ lateral to the midline. Drill holes for the earth and reference electrodes were $1 \mathrm{~mm}$ anterior to bregma, $\pm 1 \mathrm{~mm}$ from the midline, respectively. Three additional holes were drilled for the placement of mounting screws. Electrodes were made of stainless steel and insulated with polymide (PlasticsOne, Roanake, VA, USA). The recording electrode was $0.125 \mathrm{~mm}$ in diameter and $5 \mathrm{~mm}$ long. Reference and ground electrodes were $0.25 \mathrm{~mm}$ diameter and $2 \mathrm{~mm}$ long. Prior to the beginning of surgery, all electrodes and components were sterilized in $70 \%$ ethanol for 2-3 minutes and then rinsed in saline. The proximal parts of the electrodes were inserted into a matching head plug and mounted onto a stereotaxic electrode holder. The head plug ensemble was lowered down over the drill holes and electrode tips were carefully placed inside the drill holes, on top of the dura mater. Dental 
cement (Vertex-Dental, Zeist, the Netherlands) was placed around the head plug ensemble and mounting screws to firmly attach the head plug to the rat's skull. After recovery from anaesthesia, all rats were housed individually.

\section{ERP testing and analysis}

Auditory gating was measured using a modified stimulus and acquisition system (EMG startle reflex testing system, San Diego Instruments, San Diego, CA, USA), which presented all sounds and acquired EEG data simultaneously. The recording chamber was a purpose-built, ventilated, electromagnetically shielded and sound-attenuating wooden box. Three openings covered with fine aluminium mesh allowed air, light and sound to enter the chamber while remaining electromagnetically shielded. During testing, rats were positioned inside a clear, plexiglass cylinder $(12.6 \mathrm{~cm}$ diameter $)$ in the centre of the chamber and an electronic swivel was clamped near the ceiling so that rats were free to move despite being attached to a cable. Two electromagnetically shielded speakers (8030A, Genelec, Finland; frequency response predominately $55 \mathrm{~Hz}-21 \mathrm{kHz}$ ) were positioned on either side of the recording chamber to present sounds. Amplifier gain was set to $10,000 \mathrm{X}$ and sampling rate was $1000 \mathrm{~Hz}$. Analogue high and low pass filters were set to $0.05 \mathrm{~Hz}$ and $300 \mathrm{~Hz}$, respectively. Presentation of sounds and the recording of responses was completely automated using SR Lab software (San Diego Instruments). Approximately 2 weeks post-surgery, rats were acclimated to the testing chamber for a full testing session and the functionality of electrodes was verified. Drug trials commenced 2-3 days later. Each test session began with 3 minutes acclimation period of background noise ( $65 \mathrm{~dB}$ white noise). Following this, 150 trials of paired clicks ( $85 \mathrm{~dB}, 1 \mathrm{~ms}$ burst of white noise. Two clicks, $500 \mathrm{~ms}$ apart) were presented at random intervals between 10 and 20 seconds. EEG epochs for each trial were recorded 
$200 \mathrm{~ms}$ before the first click until $500 \mathrm{~ms}$ after the second click (1200 ms epochs) and then stored for offline analysis. Test sessions were conducted 2-3 days apart.

Raw epoched data was imported into the EEGlab plugin (Delorme and Makeig 2004) for Matlab where the 150 epochs could be visualised. Epochs were digitally filtered with a $0.1 \mathrm{~Hz}$ high pass filter and the baseline was removed (based on the $200 \mathrm{~ms}$ pre-stimulus data). Each epoch was visually screened for artefacts so that unsatisfactory trials could be rejected. Waveform averaging was only done on epochs free of gross movement artefacts, sleep activity and amplifier saturation artefacts. At least 30 satisfactory trials were required for waveform averaging. The resultant average waveform was then analyzed for the P1 peak and N1 trough. The N1 component was taken as the maximum negative deflection in the 20$90 \mathrm{~ms}$ range following the stimulus. The P1 amplitude was measured as the most prominent peak preceding the N1 component. Gating ratios were expressed as the magnitude of the N1 component (P1 amplitude - N1 amplitude) that occurred to the second click divided by the N1 component magnitude that occurred in response to the first click (S2/S1). An S2/S1 gating ratio of 0.5 or lower was considered normal. Gating ratios higher than 0.5 indicate a disruption of normal auditory gating. A small number of animals were excluded from data analysis because they had baseline $\mathrm{S} 2 / \mathrm{S} 1$ gating ratios greater than 0.5 and were designated as non-gaters.

\section{Drugs}

All acute drugs were dissolved in saline to an injection volume of $1 \mathrm{ml} / \mathrm{kg}$. Doses were selected on the basis of relevant literature and preliminary experiments in male rats. ERPs were acquired on 4 separate days in a pseudorandomized design so that each female rat had a recording session following administration of vehicle (saline), $0.1 \mathrm{mg} / \mathrm{kg}$ apomorphine 
(R-(-)-apomorphine hydrochloride hemihydrate; Sigma-Aldrich), $0.5 \mathrm{mg} / \mathrm{kg}$ amphetamine ((+)- $\alpha$-methylphenethylamine; Sigma-Aldrich) and $2.5 \mathrm{mg} / \mathrm{kg}$ phencyclidine (1-[1phenycylohexyl]piperone hydrochloride; Sigma-Aldrich). Male rats were tested using the same protocol except that, because of unavailability of phencyclidine, we used $0.05 \mathrm{mg} / \mathrm{kg}$ MK-801 ((5S,10R)-(+)-5-Methyl-10,11-dihydro-5H-dibenzo[a,d]cyclohepten-5,10-imine hydrogen maleate, Sigma-Aldrich). The crossover protocol allowed for within-subject statistical analysis and reduced the number of animals required. Doses and protocols were chosen on the basis of our previous experiments on the effects of estrogen and testosterone treatment on PPI (Gogos et al. 2010; Gogos et al. 2011; Gogos and van den Buuse 2003; 2004), allowing comparison of the results.

\section{Statistical Analysis}

Data are presented as mean \pm standard error of the mean (S.E.M.) of $n=8$ animals per group with succesful gonadectomy and electrode surgeries and an acceptable number of satisfactory trials in all drug conditions. Group differences were analyzed using Systat 13.0 software (SPSS, Chicago, IL, USA). Body weight and uterus weight were analyzed using one-way analysis of variance (ANOVA). Gating ratios were analyzed using two-way ANOVA with hormone treatment group as a between-subject factor and repeated measures applied for drug. P1, N1 and P1-N1 amplitudes were analyzed using two-way ANOVA with hormone treatment group as a between-subjects factor and repeated measures applied for drug and trial type (S1 or S2). Where statistically significant main effects or interactions were observed, further pair-wise comparisons were analyzed. Alpha was 0.05 for all statistical analyses. 


\section{RESULTS}

\section{Female rats: Body weights and uterus weights}

At the time of surgery there were no differences in mean body weight between treatment groups (Table 1). At the conclusion of experiments, there was a significant main effect of treatment in terms of final body weight $(\mathrm{F}(2,21)=28.9, \mathrm{P}<0.001)$, weight change from the time of surgery $(\mathrm{F}(2,21)=260.2, \mathrm{P}<0.001)$, uterus weight $(\mathrm{F}(2,21)=55.2, \mathrm{P}<0.001)$ and the ratio of uterus weight to final body weight $(\mathrm{F}(2,21)=65.9, \mathrm{P}<0.001)$. Compared to SHAMs, untreated OVX rats gained significantly more weight throughout the experiment (weight gain $\mathrm{F}(1,14)=235.4, \mathrm{P}<0.001$; final body weight $\mathrm{F}(1,14)=17.9, \mathrm{P}=0.001$; Table 1) and had lower uterus weights (uterus weight $\mathrm{F}(1,14)=150.5, \mathrm{P}<0.001$ ); uterus weight/body weight ratio $\mathrm{F}(1,14)=120.0, \mathrm{P}<0.001)$. OVX+E rats gained significantly less weight than SHAM rats (weight gain $\mathrm{F}(1,14)=61.2, \mathrm{P}<0.001$; final body weight $\mathrm{F}(1,14)=7.4, \mathrm{P}=0.017$ ) and untreated OVX rats (weight gain $\mathrm{F}(1,14)=477.2, \mathrm{P}<0.001$; final body weight $\mathrm{F}(1,14)=95.6, \mathrm{P}<0.001$ ). This was accompanied by higher uterus weights in OVX+E rats compared to SHAMs $(\mathrm{F}(1,14)=25.0, \mathrm{P}<0.001)$ and untreated $\mathrm{OVX}$ rats $(\mathrm{F}(1,14)=79.2, \mathrm{P}<0.001)$, as well as increased body weight to uterus weight ratios (compared to $\operatorname{SHAM~} \mathrm{F}(1,14)=33.0, \mathrm{P}<0.001$; OVX F(1,14)=95.9, $\mathrm{P}<0.001$; Table 1).

\section{Effects of ovariectomy and estrogen on baseline ERP in female rats}

In response to the two stimuli, S1 and S2, clear ERPs were caused within the $100 \mathrm{~ms}$ poststimulus. Example ERPs from each treatment group indicating the P1 and N1 components are shown in Figure 1. The P1 components that were observed in response to S1 and S2 occurred with a mean ( \pm S.E.M.) latency of $35 \pm 3$ ms. N1 components occurred $73 \pm 5 \mathrm{~ms}$ after $\mathrm{S} 1$ and $72 \pm 4 \mathrm{~ms}$ after $\mathrm{S} 2$. 
The effect of trial type (S1 or S2) was highly significant for P1-N1 amplitudes $(\mathrm{F}(1,21)=84.9$, $\mathrm{P}<0.001), \mathrm{P} 1(\mathrm{~F}(1,21)=31.7, \mathrm{P}<0.001)$ and $\mathrm{N} 1(\mathrm{~F}(1,21)=39.8, \mathrm{P}<0.001$; Table 2$)$, reflective of ERPs caused by S1 being consistently larger than ERPs resulting from S2, suggesting normal gating (Figure 1 and Table 2). The main effect of hormone treatment was significant for P1N1 amplitudes $(\mathrm{F}(2,21)=3.9, \mathrm{P}=0.035$; Table 2$)$, but not for $\mathrm{P} 1$ or $\mathrm{N} 1$ amplitudes. Comparison of SHAMs and untreated OVX rats showed a main effect of hormone treatment on P1-N1 amplitudes $(\mathrm{F}(1,14)=10.0, \mathrm{P}=0.007)$, reflecting lower $\mathrm{P} 1-\mathrm{N} 1$ amplitudes in response to both $\mathrm{S} 1$ and $\mathrm{S} 2$ in untreated OVX rats (Figure 1 and Table 2). P1-N1 amplitudes were also significantly reduced in untreated $\mathrm{OVX}$ rats compared to $\mathrm{OVX}+\mathrm{E}$ rats $(\mathrm{F}(1,14)=5.4, \mathrm{P}=0.035)$ and this effect was similar for S1 and S2 (lack of a trial $\mathrm{x}$ treatment interaction). There were no significant differences of P1-N1 amplitudes between SHAMs and OVX+E rats. Despite the reduction of baseline ERP amplitude that was observed in OVX rats compared to the other groups, there were no differences between groups with respect to S2/S1 ratios following saline treatment (Figure 2).

\section{Drug effects on ERPs in female rats}

Analysis of S2/S1 ratios comparing the responses to saline, apomorphine, amphetamine and phencyclidine together showed a highly significant effect of drug $(\mathrm{F}(3,63)=10.3, \mathrm{P}<0.001)$. Therefore subsequent statistical analyses of ERPs were conducted for each drug separately.

\section{Effect of apomorphine on $\mathrm{S} 2 / \mathrm{S} 1$ ratios in female rats}

Analysis of S2/S1 ratios showed that there was a significant main effect of drug $(\mathrm{F}(1,21)=18.9, \mathrm{P}<0.001)$ as well as a hormone treatment $\mathrm{x}$ drug interaction $(\mathrm{F}(2,21)=11.0$, $\mathrm{P}=0.001$; Figure 2). Apomorphine similarly increased $\mathrm{S} 2 / \mathrm{S} 1$ ratios in SHAM rats compared 
with untreated OVX rats. In contrast, there was a significant hormone treatment $\mathrm{x}$ drug interaction when $\mathrm{OVX}+\mathrm{E}$ treated rats were compared with SHAM rats $(\mathrm{F}(1,14)=17.3$, $\mathrm{P}=0.001)$ or untreated OVX rats $(\mathrm{F}(1,14)=16.6, \mathrm{P}=0.001)$, reflecting that apomorphine significantly increased S2/S1 ratios in SHAMs $(\mathrm{F}(1,7)=23.8, \mathrm{P}=0.002)$ and untreated OVX rats $(\mathrm{F}(1,7)=15.1, \mathrm{P}=0.006)$, but had no effect in $\mathrm{OVX}+\mathrm{E}$ treated rats (Figure 2).

\section{Component analysis of the effect of apomorphine in female rats}

Analysis of P1-N1 amplitudes that occurred in response to S1 and S2 following administration of saline or apomorphine revealed significant main effects of hormone treatment $(\mathrm{F}(2,21)=3.9, \mathrm{P}=0.036)$ and trial type $(\mathrm{F}(1,21)=80.6, \mathrm{P}<0.001)$ as well as a hormone treatment $\mathrm{x}$ trial type interaction $(\mathrm{F}(2,21)=4.1, \mathrm{P}=0.031)$ and an drug by trial type interaction $(\mathrm{F}(1,21)=4.9, \mathrm{P}=0.038)($ Table 2$)$.

Further analysis of P1-N1 amplitudes in each hormone group separately (Table 2) revealed significant differences between amplitudes after S1 and after S2 (main effect of trial type) in all groups. However, a drug $\mathrm{x}$ trial type interaction was only seen in SHAM rats $(\mathrm{F}(1,7)=8.43, \mathrm{P}=0.023)$ and in $\mathrm{OVX}$ rats $(\mathrm{F}(1,7)=11.7, \mathrm{P}=0.011)$ reflecting the increased S2/S1 ratio and reduced auditory gating caused by apomorphine treatment in these groups (Figure 2). In contrast, in OVX+E rats there was no drug $\mathrm{x}$ trial type interaction, reflecting the similar S2/S1 ratio after saline and apomorphine treatment in these animals (Figure 2). Other than a significant reduction of P1-N1 amplitude to S1 by apomorphine treatment in OVX rats (Table 2), there were no clear changes in these amplitudes which could explain the effect of hormone state on the action of apomorphine. 
With respect to P1 amplitudes caused by S1 and S2 (Table 2), there were significant main effects of trial type $(\mathrm{F}(1,21)=20.2, \mathrm{P}<0.001)$ and a drug $\mathrm{x}$ trial type interaction $(\mathrm{F}(1,21)=5.6$, $\mathrm{P}=0.027)$. There was also a trend for a main effect of hormone treatment $(\mathrm{F}(2,21)=3.3$, $\mathrm{P}=0.058$ ). Untreated OVX rats had lower P1 amplitudes for S1 and S2 than SHAM rats (main effect of hormone treatment, $\mathrm{F}(1,14)=7.1, \mathrm{P}=0.018$ ) and the same tendency was seen compared to $\mathrm{OVX}+\mathrm{E}$ rats $(\mathrm{F}(1,14)=3.6, \mathrm{P}=0.077)$. There was no difference between SHAM and OVX+E treated rats (Table 2).

Analysis of N1 amplitudes measured from baseline showed a significant effect of trial type $(\mathrm{F}(1,21)=30.2, \mathrm{P}<0.001$; Table 2), reflecting that $\mathrm{N} 1$ amplitudes in response to $\mathrm{S} 1$ were consistently greater (more negative) than those that occurred in response to S2 in all treatment groups. A significant hormone treatment $\mathrm{x}$ drug $\mathrm{x}$ trial type interaction $(\mathrm{F}(2,21)=6.3$, $\mathrm{P}=0.007$ ) was further investigated by analyzing $\mathrm{N} 1$ responses to $\mathrm{S} 1$ and $\mathrm{S} 2$ separately. The effect of apomorphine on $\mathrm{N} 1$ responses to $\mathrm{S} 1$ depended on the hormone state (hormone treatment $x$ drug interaction, $F(2,21)=3.6, P=0.045)$ and this was still found when SHAM rats were compared to $\mathrm{OVX}+\mathrm{E}$ rats $(\mathrm{F}(1,14)=5.3, \mathrm{P}=0.037)$. However this interaction was not significant when untreated OVX rats were compared to OVX+E rats, possibly because of the marked reduction in $\mathrm{N} 1$ amplitude in OVX rats compared to the other groups. Inspection of the data (Table 2) revealed that apomorphine tended to decrease the N1 response to S1 in SHAM rats while tending to increase it in $\mathrm{OVX}+\mathrm{E}$ rats. The effect of apomorphine on N1 responses to $\mathrm{S} 2$ did not depend on the hormone state (Table 2).

\section{Effect of amphetamine on $\mathrm{S} 2 / \mathrm{S} 1$ ratios in female rats}

Amphetamine increased $\mathrm{S} 2 / \mathrm{S} 1$ ratios in all treatment groups, indicated by a significant main effect of drug dose $(\mathrm{F}(1,21)=18.7, \mathrm{P}<0.001$; Figure 2). The drug dose $\mathrm{x}$ treatment group 
interaction was not significant, indicating that all rats responded similarly to amphetamine, irrespective of hormone treatment.

\section{Component analysis of the effect of amphetamine in female rats}

Analysis of P1-N1 amplitudes that occurred following administration of amphetamine showed significant effects of hormone treatment $(\mathrm{F}(2,21)=4.0, \mathrm{P}=0.033)$, drug $(\mathrm{F}(1,21)=44.0$, $\mathrm{P}<0.001)$ and trial type $(\mathrm{F}(1,22)=87.3, \mathrm{P}<0.001)$, as well a drug $\mathrm{x}$ trial type interaction $(\mathrm{F}(1,22)=56.1, \mathrm{P}<0.001)$ reflecting the reduced $\mathrm{S} 2 / \mathrm{S} 1$ ratio in all groups (Table 2$)$. Further analysis showed significant differences between hormone treatment groups when untreated OVX rats were compared with SHAMs $(\mathrm{F}(1,14)=9.0, \mathrm{P}=0.009)$ or $\mathrm{OVX}+\mathrm{E}$ rats $(\mathrm{F}(1,14)=5.7$, $\mathrm{P}=0.032$ ), reflective that $\mathrm{P} 1-\mathrm{N} 1$ amplitudes that occurred in response to $\mathrm{S} 1$ and $\mathrm{S} 2$ were consistently lower in untreated OVX rats compared to the other groups. With respect to the effect of amphetamine, when hormone groups were analyzed separately, there were drug $\mathrm{x}$ trial type interactions in SHAM rats $(\mathrm{F}(1,7)=21.9, \mathrm{P}=0.002)$, untreated OVX rats $(\mathrm{F}(1,7)=14.0, \mathrm{P}=0.007)$ as well as in $\mathrm{OVX}+\mathrm{E}$ rats $(\mathrm{F}(1,7)=21.1, \mathrm{P}=0.003)$.

Analysis of P1 amplitudes revealed significant main effects of hormone treatment $(\mathrm{F}(2,21)=3.5, \mathrm{P}=0.049), \operatorname{drug}(\mathrm{F}(1,21)=20.6, \mathrm{P}<0.001)$ and trial type $(\mathrm{F}(1,21)=48.2, \mathrm{P}<0.001)$, as well as a drug $\mathrm{x}$ trial type interaction $(\mathrm{F}(1,21)=13.1, \mathrm{P}=0.002)$ (Table 2). Investigation of the main effect of hormone treatment showed that differences were observed when untreated OVX rats were compared to SHAMs (main effect of hormone treatment, $F(1,14)=7.5$, $\mathrm{P}=0.016)$ although the comparison with $\mathrm{OVX}+\mathrm{E}$ rats did not reach significance $(\mathrm{F}(1,14)=3.3$, $\mathrm{P}=0.089$ ). There were no differences between groups when comparing SHAM and OVX+E rats with respect to P1 amplitudes. This reflects the consistent finding that untreated OVX rats had smaller ERPs to S1 and S2 than SHAMs or OVX+E rats. The significant main effect 
of drug and lack of a significant hormone treatment $\mathrm{x}$ drug or hormone treatment $\mathrm{x}$ drug $\mathrm{x}$ trial type interaction indicates that compared to saline, amphetamine reduced the P1 amplitude to S1 and S2 in all treatment groups similarly. However, when hormone groups were analyzed separately, the drug $\mathrm{x}$ trial type interactions only reached significance in SHAM rats $(\mathrm{F}(1,7)=11.5, \mathrm{P}=0.011)$. Further analysis of the drug $\mathrm{x}$ trial type interaction revealed that amphetamine reduced $\mathrm{P} 1$ amplitudes that occurred in response to $\mathrm{S} 1$ $(\mathrm{F}(1,21)=19.6, \mathrm{P}<0.001)$ and $\mathrm{S} 2(\mathrm{~F}(1,21)=19.7, \mathrm{P}<0.001)$. These responses to amphetamine treatment were not significantly dependent on the hormone state of the animals (Table 2).

With respect to the $\mathrm{N} 1$, there were significant main effects of drug $(\mathrm{F}(1,21)=14.4, \mathrm{P}=0.001)$, trial type $(\mathrm{F}(1,21)=24.4, \mathrm{P}<0.001)$ and a drug $\mathrm{x}$ trial type interaction $(\mathrm{F}(1,21)=23.6, \mathrm{P}<0.001)$. There was no effect of hormone treatment on N1 amplitudes following amphetamine indicating that all rats responded similarly (Table 2). The drug x trial type interaction was significant in the SHAM group $(\mathrm{F}(1,7)=25.2, \mathrm{P}=0.002)$ and a strong trend was found in untreated OVX rats $(\mathrm{F}(1,7)=5.1, \mathrm{P}=0.057)$ and in $\mathrm{OVX}+\mathrm{E}$ rats $(\mathrm{F}(1,7)=4.9, \mathrm{P}=0.063)$. Further analysis of the drug $\mathrm{x}$ trial type interaction revealed that amphetamine reduced $\mathrm{N} 1$ amplitudes that occurred in response to $\mathrm{S} 1(\mathrm{~F}(1,21)=20.8, \mathrm{P}<0.001)$ but not to $\mathrm{S} 2$, irrespective of the hormone state of the animals.

\section{Effect of phencyclidine on S2/S1 ratios in female rats}

Similar to what was observed following amphetamine, phencyclidine increased S2/S1 gating ratios in all treatment groups when compared to saline treatment $(\mathrm{F}(1,21)=40.9, \mathrm{P}<0.001$; Figure 2). The lack of a main effect of hormone treatment or a drug $\mathrm{x}$ hormone treatment interaction indicated similar phencyclidine effects in all animals. 


\section{Component analysis of the effect of phencyclidine in female rats}

Analysis of P1-N1 amplitudes that occurred following administration of phencyclidine showed significant effects of $\operatorname{drug}(\mathrm{F}(1,21)=18.7, \mathrm{P}<0.001)$, trial type $(\mathrm{F}(1,21)=91.0$, $\mathrm{P}<0.001)$, as well as a drug $\mathrm{x}$ trial type interaction $(\mathrm{F}(1,21)=41.7, \mathrm{P}<0.001)$. This drug $\mathrm{x}$ trial type interaction was significant in all hormone groups $(\mathrm{F}(1,7)=28.7, \mathrm{P}=0.001$ in SHAM rats; $\mathrm{F}(1,7)=17.7, \mathrm{P}=0.004$ in $\mathrm{OVX}$ rats; $\mathrm{F}(1,7)=9.0, \mathrm{P}=0.020$ in $\mathrm{OVX}+\mathrm{E}$ rats $)$. Compared to saline treatment, phencyclidine significantly reduced P1-N1 amplitudes that occurred to S1 $(\mathrm{F}(1,21)=25.6, \mathrm{P}<0.001)$ as well as to $\mathrm{S} 2(\mathrm{~F}(1,21)=7.8, \mathrm{P}=0.011)$, irrespective of the hormone state of the animals.

Inspection of $\mathrm{P} 1$ amplitudes revealed significant main effects of drug $(\mathrm{F}(1,21)=6.0, \mathrm{P}=0.023)$ and trial type $(\mathrm{F}(1,21)=30.5, \mathrm{P}<0.001)$ as well as a drug $\mathrm{x}$ trial type interaction $(\mathrm{F}(1,21)=12.3$, $\mathrm{P}=0.002)$. When compared to saline, phencyclidine significantly reduced $\mathrm{P} 1$ amplitudes in all treatment groups similarly, indicated by a lack of a hormone treatment $\mathrm{x}$ drug interaction. However, when hormone groups were analyzed separately, the drug x trial type interaction only reached significance in SHAM rats $(\mathrm{F}(1,7)=8.2, \mathrm{P}=0.024)$. Phencyclidine treatment reduced $\mathrm{P} 1$ amplitudes that occurred in response to $\mathrm{S} 1(\mathrm{~F}(1,21)=8.0, \mathrm{P}=0.010)$, but its effect on S2 did not reach statistical significance, nor were there interactions with hormone state (Table 2).

Compared to saline, phencyclidine significantly reduced the amplitude of the N1 component, indicated by a significant main effect of drug $(\mathrm{F}(1,21)=34.2, \mathrm{P}<0.001$; Table 2$)$. The effect of trial type was also significant $(\mathrm{F}(1,21)=33.9, \mathrm{P}<0.001)$ as well as a drug $\mathrm{x}$ trial type interaction $(\mathrm{F}(1,21)=24.3, \mathrm{P}<0.001)$. There was no effect of the hormone treatments on $\mathrm{N} 1$ amplitudes in terms of the response to phencyclidine. Pair-wise comparisons showed that 
phencyclidine significantly reduced the N1 component amplitude that occurred due to S1 $(\mathrm{F}(1,21)=44.0, \mathrm{P}<0.001)$ and showed a trend for a reduction for responses to $\mathrm{S} 2(\mathrm{~F}(1,21)=3.8$, $\mathrm{P}=0.066$ ), independent of the hormone state of the animals (Table 2).

\section{Body weights and seminal vesicle weight in male rats}

There were no differences in body weight between the three hormone treatment groups at the time of surgery. However, there was a trend for a difference in final body weights $(\mathrm{F}(2,25)=2.8, \mathrm{P}=0.077)$, as well as a significant effect of hormone treatment on body weight gain from the time of surgery until the end of the experiment $(\mathrm{F}(2,25)=13.8, \mathrm{P}<0.001$; Table 3). Sham-operated rats gained significantly more weight than untreated CAST rats $(\mathrm{F}(1,15)=27.7, \mathrm{P}<0.001)$ and $\mathrm{CAST}+\mathrm{DHT}$ rats $(\mathrm{F}(1,17)=16.6, \mathrm{P}=0.001)$. There were no differences when comparing untreated CAST rats and CAST+DHT rats in terms of body weight gain or final body weights.

There was a main effect of hormone treatment with respect to seminal vesicle weight $(\mathrm{F}(2,25)=147.7, \mathrm{P}<0.001)$ and the ratio of seminal vesicle weight to final body weight $(\mathrm{F}(2,25)=264.3, \mathrm{P}<0.001)$. Compared to SHAMs, untreated CAST rats had significantly smaller seminal vesicles $(\mathrm{F}(1,15)=175.1, \mathrm{P}<0.001)$ and seminal vesicle to body weight ratios $(\mathrm{F}(1,15)=592.1, \mathrm{P}<0.001)$. Similarly, when compared to untreated CAST rats, CAST $+\mathrm{DHT}$ rats had larger seminal vesicles $(\mathrm{F}(1,18)=735.2, \mathrm{P}<0.001)$ and seminal vesicle to body weight ratios $(\mathrm{F}(1,21)=484.7, \mathrm{P}<0.001)$. There were no differences in seminal vesicle weight or ratios when comparing SHAMs and CAST+DHT rats. 


\section{Drug effects on ERPs in male rats}

When all drug treatments (saline, apomorphine, amphetamine and MK-801) were analyzed together there were significant main effects of drug on $\mathrm{S} 2 / \mathrm{S} 1$ ratios $(\mathrm{F}(3,75)=12.4, \mathrm{P}<0.001)$. Therefore each drug was subsequently compared to saline and analyzed separately.

\section{Effect of apomorphine on $\mathrm{S} 2 / \mathrm{S} 1$ ratios in male rats}

Compared to saline treatment, apomorphine caused a significant increase in S2/S1 ratios $(\mathrm{F}(1,25)=12.6, \mathrm{P}=0.002$; Figure 3$)$, indicating a disruption of sensory gating. There were no effects of the hormone treatment or interactions, indicating that all treatment groups responded similarly following apomorphine treatment.

\section{Component analysis of the effect of apomorphine in male rats}

Analysis of P1-N1 amplitudes showed a significant main effect of trial type $(F(1,25)=63.2$, $\mathrm{P}<0.001)$, as well as an interaction of drug dose and trial type $(\mathrm{F}(1,25)=20.6, \mathrm{P}<0.001)$. Further analysis showed that compared to saline, apomorphine treatment reduced P1-N1 amplitudes that occurred to $\mathrm{S} 1(\mathrm{~F}(1,25)=10.6, \mathrm{P}=0.003)$, but did not change responses to $\mathrm{S} 2$ (Table 4).

Compared to saline, apomorphine treatment reduced P1 amplitudes, indicated by a significant main effect of dose $(\mathrm{F}(1,25)=4.3, \mathrm{P}=0.048)$. The effect of trial-type was also significant $(\mathrm{F}(1,25)=26.6, \mathrm{P}<0.001)$, reflective of $\mathrm{P} 1$ amplitudes that resulted from $\mathrm{S} 1$ being consistently larger than responses to S2. Additionally a drug dose $\mathrm{x}$ trial type interaction was significant $(\mathrm{F}(1,25)=16.8, \mathrm{P}<0.001)$ which showed that apomorphine reduced the $\mathrm{P} 1$ amplitude to $\mathrm{S} 1$ $(\mathrm{F}(1,25)=12.0, \mathrm{P}=0.002)$, but did not change responses to $\mathrm{S} 2$ (Table 4$)$. There were no effects 
of castration of testosterone treatment or significant interactions with respect to P1 amplitudes following apomorphine.

The main effect of trial type was significant $(F(1,25)=17.7, \mathrm{P}<0.001$; Table 4$)$, reflective of N1 amplitudes that occurred to S1 being larger than those that occurred due to S2. Further analysis showed that the effect of trial type was significant following saline $(F(1,25)=23.5$, $\mathrm{P}<0.001$ ) and apomorphine $\mathrm{F}(1,25)=6.6, \mathrm{P}=0.017)$. There was no effect of the hormone treatment or apomorphine injection on N1 amplitudes.

\section{Effect of amphetamine on $\mathrm{S} 2 / \mathrm{S} 1$ ratios in male rats}

Compared to saline treatment, amphetamine caused a significant increase in S2/S1 ratios $(\mathrm{F}(1,25)=24.8, \mathrm{P}<0.001)$. There were no effects of the hormone treatment, indicating that all treatment groups responded similarly following amphetamine treatment with respect to S2/S1 ratios (Figure 3).

\section{Component analysis of the effect of amphetamine in male rats}

There were significant effects of drug dose $(\mathrm{F}(1,25)=32.6, \mathrm{P}<0.001)$, trial type $(\mathrm{F}(1,25)=55.3$, $\mathrm{P}<0.001)$, as well as a drug dose $\mathrm{x}$ trial type interaction $(\mathrm{F}(1,25)=61.5, \mathrm{P}<0.001)$ on $\mathrm{P} 1-\mathrm{N} 1$ amplitudes. Further analysis showed that when compared to saline, amphetamine decreased the P1-N1 amplitude that occurred in response to $\mathrm{S} 1(\mathrm{~F}(1,25)=48.4, \mathrm{P}<0.001)$, as well as responses to $\mathrm{S} 2(\mathrm{~F}(1,25)=8.6, \mathrm{P}=0.009$; Table 4). However the reduction of $\mathrm{P} 1-\mathrm{N} 1$ amplitude following amphetamine was much more pronounced on responses to S1 than to S2 (Table 4).

Analysis of P1 amplitudes showed that main effects of trial type $(\mathrm{F}(1,25)=24.3, \mathrm{P}<0.001)$ and dose of amphetamine $(\mathrm{F}(1,25)=10.5, \mathrm{P}=0.003)$ were significant, as well as an interaction of 
trial type and drug dose $(\mathrm{F}(1,25)=32.2, \mathrm{P}<0.001)$. Further analysis showed that compared to saline, amphetamine reduced $\mathrm{P} 1$ amplitudes that occurred to $\mathrm{S} 1(\mathrm{~F}(1,25)=23.2, \mathrm{P}<0.001)$, but did not change responses to S2 (Table 4).

With respect to $\mathrm{N} 1$ amplitudes, there were significant effects of trial type $(\mathrm{F}(1,25)=29.8$, $\mathrm{P}<0.001)$, amphetamine dose $(\mathrm{F}(1,25)=8.0, \mathrm{P}=0.009)$, as well as a drug dose $\mathrm{x}$ trial type interaction $(\mathrm{F}(1,25)=4.8, \mathrm{P}=0.038)$. Further analysis showed that compared to saline, amphetamine decreased the $\mathrm{N} 1$ amplitude that occurred in response to $\mathrm{S} 1(\mathrm{~F}(1,25)=9.8$, $\mathrm{P}=0.004)$, but did not change responses to $\mathrm{S} 2$ (Table 4).

\section{Effect of MK-801 on S2/S1 ratios in male rats}

Compared to saline treatment, MK-801 caused a significant increase in S2/S1 ratios $(\mathrm{F}(1,25)=43.8, \mathrm{P}<0.001)$. However there were no effects of the hormone treatment or significant interactions, indicating that all treatment groups responded similarly after MK-801 treatment (Figure 3).

\section{Component analysis of the effect of MK-801 in male rats}

Analysis of P1-N1 amplitudes following administration of MK-801 showed a significant main effect of trial type $(\mathrm{F}(1,25)=53.1, \mathrm{P}<0.001)$, dose of MK-801 $(\mathrm{F}(1,25)=18.7, \mathrm{P}<0.001)$, as well as an interaction of MK-801 dose and trial type $(\mathrm{F}(1,25)=80.1, \mathrm{P}<0.001)$. Further investigation showed that MK-801 reduced the P1-N1 amplitude that occurred to S1 $(\mathrm{F}(1,25)=37.7, \mathrm{p}<0.001)$ but did not change responses to S2 (Table 4).

Analysis of P1 amplitudes following administration of MK-801 showed a significant main effect of trial type $(\mathrm{F}(1,25)=22.9, \mathrm{P}<0.001)$ as well as an interaction of drug dose and trial 
type $(\mathrm{F}(1,25)=39.9, \mathrm{P}<0.001)$. Further analysis showed that MK-801 reduced the $\mathrm{P} 1$ amplitude that occurred to $\mathrm{S} 1(\mathrm{~F}(1,25)=11.3, \mathrm{P}=0.002)$ but did not change responses to $\mathrm{S} 2$ (Table 4). There were no effects of hormone treatment or significant interactions indicating that all hormone groups responded similarly to MK-801 with respect to P1 amplitudes.

There was a significant main effect of trial type $(\mathrm{F}(1,25)=18.0, \mathrm{P}<0.001)$, dose of MK-801 $(\mathrm{F}(1,25)=21.9, \mathrm{P}<0.001)$, as well as an interaction of trial type and dose $(\mathrm{F}(1,25)=6.1$, $\mathrm{P}=0.021)$ on $\mathrm{N} 1$ amplitudes. Compared to saline, MK-801 caused reduced N1 amplitudes that occurred to $\mathrm{S} 1(\mathrm{~F}(1,25)=18.9, \mathrm{P}<0.001)$ as well as $\mathrm{S} 2(\mathrm{~F}(1,25)=8.7, \mathrm{P}=0.007$; Table 4). 


\section{DISCUSSION}

The present study investigated the effect of estrogen replacement in ovariectomized female rats and testosterone replacement in castrated male rats on the ERP responses to pairs of auditory stimuli. The animals were tested following administration of the dopamine D1/D2 receptor agonist, apomorphine, the dopamine releaser, amphetamine or the NMDA receptor antagonists, phencyclidine or MK-801. The main finding was that estrogen replacement in ovariectomized rats prevented a disruption of auditory sensory gating caused by apomorphine. Compared to saline treatment, apomorphine increased S2/S1 gating ratios in SHAM rats and untreated OVX rats but it had no effect on $\mathrm{S} 2 / \mathrm{S} 1$ gating ratios in $\mathrm{OVX}+\mathrm{E}$ rats. We also observed a generalized reduction of ERPs in OVX rats compared to SHAM rats and this reduction was reversed by estrogen replacement. Estrogen replacement did not affect the action of amphetamine or phencyclidine on sensory gating ratios. In contrast to female rats, there were no differences between castrated male rats and sham-operated controls, irrespective of testosterone replacement.

While estrogen treatment markedly reduced the effect of apomorphine on S2/S1 ratio, its effect on individual ERP components was subtle. Apomorphine significantly reduced the P1N1 difference compared to saline in SHAM rats and untreated OVX rats, but this effect was diminished in $\mathrm{OVX}+\mathrm{E}$ rats. There were no clear effects of apomorphine on either the P1-N1 amplitude or the P1 amplitude and there were no interactions with hormone state. However, apomorphine tended to decrease the $\mathrm{N} 1$ response to $\mathrm{S} 1$ in SHAM rats while tending to increase it in $\mathrm{OVX}+\mathrm{E}$ rats, leading to a significant hormone state $\mathrm{x}$ drug interaction. This reversal of the effect of apomorphine on the N1 amplitude to S1 was not observed for S2 nor with respect to the effects of amphetamine or phencyclidine. The mechanisms or specific 
pathways through which estrogen would affect the N1 response amplitude to S1 remain to be determined.

The primary therapeutic target of antipsychotic medications is dopamine D2 receptors in mesolimbic dopaminergic pathways. Considering that antipsychotic drugs can ameliorate auditory gating deficits in humans (Light et al. 2000; Oranje et al. 2013) and rodents (Adler et al. 1988; Adler et al. 1986; Dissanayake et al. 2009), it follows that the beneficial actions of estrogen in this model are possibly mediated by altering the expression of dopamine receptor densities (particularly the D2 subtype) in these brain areas. Estrogen exerts potent tonic and dynamic control of dopaminergic neurotransmission (Di Paolo 1994; McGrath et al. 2008). We previously observed in similarly treated female rats, that estrogen treatment reduced dopamine D2 receptor densities in the caudate nucleus and nucleus accumbens of OVX rats (Chavez et al. 2010). Such a reduction in these brain areas would provide a straightforward explanation as to why apomorphine failed to cause a disruption of auditory gating in $\mathrm{OVX}+\mathrm{E}$ rats. Similar binding studies have not been done in male rats treated in the same way as the present studies.

Amphetamine disrupted auditory gating in all treatment groups, irrespective of ovariectomy/estrogen treatment or castration/testosterone treatment. The main mechanism of action of amphetamine involves an interaction with the dopamine transporter on dopamine nerve terminals and vesicles, leading to enhanced extracellular levels of dopamine and postsynaptic activation of dopamine D1 and D2 receptors, theoretically similar to exogenous administration of apomorphine. Therefore, the lack of effect of estrogen replacement on amphetamine-induced ERP disruptions was surprising. However, there are a number of points which could explain this apparent discrepancy. In our previous binding studies (Chavez et al. 
2010), estrogen not only reduced dopamine D2 receptor density in the nucleus accumbens and caudate nucleus of OVX rats, but it also caused an increase of dopamine transporter density in these brain regions. It is possible that this increased density of the dopamine transporter functionally compensated for the reduced dopamine D2 levels, effectively maintaining the disrupting effect of amphetamine on sensory gating. Furthermore it should be noted, that amphetamine also causes the release of other monoamines, especially noradrenaline, which has been shown to alter auditory gating on its own (Keedy et al. 2007; Kokkinidis and Anisman 1980; Stevens et al. 1991). For example, amphetamine-induced disruptions of auditory gating were attenuated by the $\alpha$-adrenoceptor antagonist phentolamine, the $\beta$-adrenoceptor antagonist timolol as well as the dopamine D1 receptor antagonist SCH 23390 (Stevens et al. 1991). In that study the dopamine D2 receptor antagonist sulpiride did not attenuate the amphetamine-induced disruptions, however the dopamine D2 receptor antagonist haloperidol has been shown to reverse amphetamine-induced disruptions of auditory gating in several other studies (Adler et al. 1988; Adler et al. 1986; Bickford-Wimer et al. 1990). A further explanation as to why OVX and estrogen replacement had no effect on amphetamine-induced disruptions of auditory gating could be that the dose of amphetamine that we selected $(0.5 \mathrm{mg} / \mathrm{kg})$ was too high to allow for reversal by estrogen to be observed (Bisagno et al. 2003; Simpson and Kelly 2012). Therefore, future experiments should focus on the modulation by estrogen of the effect of lower doses of amphetamine on auditory gating and also confirm the involvement of dopamine receptors. Future studies should also include receptor binding studies in male rats which could elucidate the apparent lack of effect of castration and hormone treatment in the present study as opposed to previous PPI studies (Gogos and van den Buuse 2003). 
Ovariectomy and estrogen replacement had no effect on disruptions of auditory gating caused by phencyclidine in female rats and there were no effects of castration or testosterone treatment on MK-801-induced disruptions in male rats. Adler et al. (1986) showed that phencyclidine-induced disruptions of auditory gating are attenuated by the dopamine D2 receptor antagonist drug haloperidol, suggesting that these receptors are required for a phencyclidine-induced disruption. Dopaminergic neurons from the basal ganglia project onto glutamatergic neurons in the cortex, inhibiting those neurons and causing a net reduction in cortical glutamatergic neuronal firing rate (Carlsson et al. 2001). Although phencyclidine and MK-801 block the glutamate NMDA receptor subtype, this ultimately causes an increase in synaptic levels of glutamate and a net increase in signalling through other non-NMDA glutamate receptors, such as AMPA and metabotropic glutamate receptors (Morris et al. 2005). This complex neuronal circuitry is not well understood and other neuronal subtypes such as GABA, acetylcholine, noradrenaline and 5-HT neurons are also implicated in the effects of NMDA receptor blockade (Carlsson et al. 1999; Carlsson et al. 2001; Svenningsson et al. 2003). Overall, however, if dopaminergic mechanisms do not play a major role in the effects of phencyclidine or MK-801, this could explain the lack of an effect of estrogen. We recently verified a possible involvement of dopamine receptors in the action of phencyclidine on sensory gating. Thus, preliminary data from male rats showed that haloperidol pretreatment completely blocked the disruption of sensory gating caused by amphetamine and apomorphine treatment but it had no significant effect on the action of phencyclidine (Thwaites, Gogos and Van den Buuse, unpublished).

An additional and unexpected finding was that untreated OVX rats had consistently lower ERP amplitudes than SHAMs or OVX+E rats. Despite this reduction in the ERP amplitudes in untreated OVX rats, all treatment groups still had intact $\mathrm{S} 2 / \mathrm{S} 1$ gating ratios after injection 
of saline. Smaller baseline ERP voltage amplitudes are often reflective of lower impedance of the implanted electrodes, however this is unlikely to account for the hormone-induced variation of amplitudes because the selection of rats and all surgeries were randomised. The impedance of electrodes was not routinely measured in the present study, which could have ruled out this possibility. However, in a previous cohort of rats we observed that the impedances that result from the electrode implantation surgery were between 80 and 180 $\mathrm{kOhm}$ (unpublished data); impedances that occur outside of this range cause obvious artefacts in the EEG signal. The effects of sex steroids on ERP amplitudes in the paired-click paradigm have received little attention, however in studies of mismatch negativity, ERP amplitudes varied with hormone replacement therapy (SANE 2002) and throughout the menstrual cycle (Bayer et al. 1999). Furthermore, there were gender differences in EEG amplitudes at rest as well as during photic stimulation (Choy et al. 2009), showing resting hormone state may affect the ERP amplitudes.

Despite the marked reduction of ERP component amplitudes between sham-operated rats and untreated OVX rats, there were no significant effects on the action of apomorphine. Although we did not measure circulating levels of estrogen, organ and body weights were consistent with a marked decrease of estrogen levels in the OVX rats. It could then be expected that the effect of apomorphine would be enhanced in these animals i.e. the reverse of the attenuation of the apomorphine effect in OVX+E rats. In our previous binding studies (Chavez et al. 2010) we observed a significant increase of dopamine D2 receptor density in OVX rats compared to intact, sham-operated rats and this could be a mechanism to explain such an increase. However, there were no significant differences between untreated OVX rats and sham-operated controls in terms of the disruption of S2/S1 ratios caused by any of the drugs, similar to what we have previously found with PPI (Gogos et al. 2010; Gogos and Van den 
Buuse 2004). It is not clear why such an effect of a lack of estrogen (in OVX rats vs. SHAM rats) was not seen, but it is possible that the generally lower component amplitudes in this group masked any change of the effect of apomorphine. Alternatively, the relatively subtle effect of apomorphine at this dose may represent a ceiling effect which cannot be further enhanced by the loss of estrogen. Further experiments are needed to address these points.

In conclusion, these results suggest that chronic, high levels of estrogen can block the effect of apomorphine on auditory sensory gating. Thus, estrogen may alter dopaminergic neuronal activity in a way that is beneficial for treating the sensory gating deficits that are observed in schizophrenia patients. Although the side effect profile of estrogen treatment limits its practical use, the mechanism by which estrogen exerts these changes to dopaminergic systems should be investigated further. Newer, more selective drugs such as the class of selective estrogen receptor modulators (SERMs) may provide a promising treatment approach. 
TABLE 1: Body weight (BW) at the start and end of the experiment, weight gain during the experiment, and final uterus weight of sham-operated controls, ovariectomized rats (OVX) and OVX rats replaced with estrogen $(\mathrm{OVX}+\mathrm{E})$.

\begin{tabular}{cccccc}
\hline $\begin{array}{l}\text { Group } \\
(\mathrm{n}=8)\end{array}$ & $\begin{array}{c}\text { BW at } \\
\text { surgery }(\mathrm{g})\end{array}$ & $\begin{array}{c}\text { Final BW } \\
(\mathrm{g})\end{array}$ & $\begin{array}{c}\text { Weight } \\
\text { gain }(\mathrm{g})\end{array}$ & $\begin{array}{c}\text { Uterus weight } \\
(\mathrm{mg})\end{array}$ & $\begin{array}{c}\text { Uterus } \\
\text { weight/BW }\end{array}$ \\
\hline SHAM & $249 \pm 8$ & $281 \pm 9$ & $32 \pm 3$ & $600 \pm 35$ & $2.15 \pm 0.15$ \\
OVX & $235 \pm 4$ & $323 \pm 4^{*}$ & $88 \pm 3^{*}$ & $151 \pm 9 *$ & $0.47 \pm 0.03^{*}$ \\
OVX+E & $252 \pm 5$ & $253 \pm 6^{* \#}$ & $2 \pm 3^{* \#}$ & $1230 \pm 12$ **\# $^{*}$ & $4.87 \pm 0.45^{* \#}$ \\
\hline
\end{tabular}

$* \mathrm{P}<0.05$ compared to sham-operated rats

${ }^{\#} \mathrm{P}<0.05$ compared to untreated OVX rats 
TABLE 2: $\mathrm{S} 1$ and $\mathrm{S} 2$ component amplitudes $(\mu \mathrm{V})$ ) in female rats after administration of saline, $0.1 \mathrm{mg} / \mathrm{kg}$ of apomorphine, $0.5 \mathrm{mg} / \mathrm{kg}$ of amphetamine or $2.5 \mathrm{mg} / \mathrm{kg}$ of phencyclidine. The animals were sham-operated (SHAM), ovariectomized (OVX) or OVX and treated with 17ß-estradiol (OVX+E). There were $\mathrm{n}-8$ rats per group.

\begin{tabular}{|c|c|c|c|c|c|c|}
\hline \multirow[b]{2}{*}{ Group } & \multicolumn{2}{|c|}{ P1-N1 } & \multicolumn{2}{|c|}{ P1 } & \multicolumn{2}{|c|}{ N1 } \\
\hline & S1 & $\mathbf{S} 2$ & S1 & S2 & S1 & $\mathbf{S 2}$ \\
\hline \multicolumn{7}{|l|}{ SHAM } \\
\hline Saline & $121.5 \pm 20.1$ & $56.5 \pm 9.7^{\#}$ & $79.1 \pm 14.9$ & $38.4 \pm 9.3^{\#}$ & $-42.5 \pm 9.8$ & $-18.1 \pm 8.3^{\#}$ \\
\hline Apomorphine & $114.2 \pm 32.6$ & $73.5 \pm 21.5^{\#}$ & $83.8 \pm 26.5$ & $55.2 \pm 17.3$ & $-30.4 \pm 8.6$ & $-18.3 \pm 6.9^{\#}$ \\
\hline Amphetamine & $40.1 \pm 11.2^{*}$ & $31.3 \pm 8.3^{\#}$ & $32.0 \pm 7.1^{*}$ & $19.0 \pm 6.2^{\#}$ & $-8.1 \pm 6.1^{*}$ & $-12.3 \pm 5.9$ \\
\hline Phencyclidine & $58.0 \pm 16.2^{*}$ & $35.0 \pm 10.8^{\# *}$ & $44.4 \pm 11.8$ & $25.9 \pm 6.4$ & $-13.6 \pm 8.0 *$ & $-9.1 \pm 5.7$ \\
\hline \multicolumn{7}{|l|}{ OVX } \\
\hline Saline & $57.0 \pm 7.3^{\dagger}$ & $22.9 \pm 2.7^{\dagger \#}$ & $30.9 \pm 8.6^{\dagger}$ & $16.1 \pm 3.0^{\#}$ & $-26.1 \pm 5.5$ & $-6.8 \pm 2.0^{\#}$ \\
\hline Apomorphine & $43.1 \pm 7.1^{\dagger^{*}}$ & $28.4 \pm 5.6^{\dagger \#}$ & $20.4 \pm 4.6^{\dagger}$ & $21.0 \pm 4.2^{\dagger}$ & $-22.6 \pm 7.3$ & $-7.4 \pm 2.5^{\#}$ \\
\hline Amphetamine & $21.5 \pm 3.3^{\dagger^{*}}$ & $13.0 \pm 2.4^{\dagger \#^{*}}$ & $14.6 \pm 2.6^{*}$ & $9.1 \pm 4.0$ & $-6.9 \pm 2.1^{*}$ & $-3.9 \pm 1.7$ \\
\hline Phencyclidine & $33.6 \pm 6.3^{*}$ & $19.9 \pm 4.3^{\#}$ & $22.6 \pm 7.2^{\dagger}$ & $14.5 \pm 4.8$ & $-11.0 \pm 3.4^{*}$ & $-5.4 \pm 1.8$ \\
\hline \multicolumn{7}{|l|}{ OVX+E } \\
\hline Saline & $108.1 \pm 22.2^{\wedge}$ & $53.6 \pm 11.7^{\wedge \#}$ & $71.4 \pm 20.5^{\wedge}$ & $40.9 \pm 10.5^{\#}$ & $-36.7 \pm 10.1$ & $-12.7 \pm 2.6^{\#}$ \\
\hline Apomorphine & $102.0 \pm 20.3^{\wedge}$ & $44.6 \pm 8.6^{\wedge \#}$ & $50.2 \pm 20.4^{\wedge}$ & $29.2 \pm 7.7^{\wedge}$ & $-51.8 \pm 18.5$ & $-15.4 \pm 6.9^{\#}$ \\
\hline Amphetamine & $29.4 \pm 6.6^{\wedge *}$ & $21.9 \pm 4.8^{\# \wedge *}$ & $10.6 \pm 5.9^{*}$ & $3.4 \pm 3.1^{*}$ & $-18.7 \pm 9.9$ & $-18.5 \pm 4.4$ \\
\hline Phencyclidine & $49.4 \pm 12.2$ & $32.1 \pm 7.4^{\#}$ & $36.2 \pm 15.1^{\wedge}$ & $23.1 \pm 8.4$ & $-13.2 \pm 6.6^{*}$ & $-9.0 \pm 5.5$ \\
\hline
\end{tabular}


* $\mathrm{P}<0.05$ compared to saline treatment in the same hormone group.

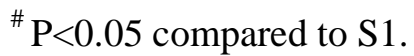

${ }^{\dagger} \mathrm{P}<0.05$ compared to similarly treated SHAM rats.

$\wedge \mathrm{P}<0.05$ compared to similarly treated OVX rats. 
TABLE 3: Body weight (BW) at the start and end of the experiment, weight gain during the experiment, and final seminal vesicle weight of sham-operated controls (SHAM), castrated rats (CAST) and CAST rats replaced with dihydrotestosterone (CAST+DHT).

\begin{tabular}{lccccc}
\hline Group & $\begin{array}{c}\text { BW at } \\
\text { surgery } \\
(\mathrm{g})\end{array}$ & $\begin{array}{c}\text { Final } \\
\text { BW }(\mathrm{g})\end{array}$ & $\begin{array}{c}\text { Weight } \\
\text { gain }(\mathrm{g})\end{array}$ & $\begin{array}{c}\text { Seminal } \\
\text { vesicle } \\
\text { weight }(\mathrm{mg})\end{array}$ & $\begin{array}{c}\text { Seminal } \\
\text { vesicle } \\
\text { weight/BW }\end{array}$ \\
\hline SHAM & $389 \pm 19$ & $497 \pm 23$ & $109 \pm 7$ & $1585 \pm 118$ & $3.17 \pm 0.13$ \\
CAST & $395 \pm 9$ & $456 \pm 10$ & $61 \pm 5^{*}$ & $117 \pm 7^{*}$ & $0.26 \pm 0.01^{*}$ \\
CAST+DHT & $386 \pm 7$ & $457 \pm 10$ & $70 \pm 6^{*}$ & $1419 \pm 43^{\#}$ & $3.12 \pm 0.12^{\#}$ \\
\hline
\end{tabular}

* $\mathrm{P}<0.05$ compared to sham-operated rats

${ }^{\#} \mathrm{P}<0.05$ compared to untreated CAST rats 
TABLE 4: $\mathrm{S} 1$ and $\mathrm{S} 2$ component amplitudes $(\mu \mathrm{V})$ in male rats after administration of saline, $0.1 \mathrm{mg} / \mathrm{kg}$ of apomorphine, $0.5 \mathrm{mg} / \mathrm{kg}$ of amphetamine or $0.05 \mathrm{mg} / \mathrm{kg}$ of MK-801. The animals were sham-operated (SHAM), castrated (CAST) or CAST rats treated with dihydrodihydrotestosterone (CAST+DHT).

\begin{tabular}{|c|c|c|c|c|c|c|}
\hline \multirow[b]{2}{*}{ Group } & \multicolumn{2}{|c|}{ P1-N1 } & \multicolumn{2}{|c|}{ P1 } & \multicolumn{2}{|c|}{ N1 } \\
\hline & S1 & $\mathbf{S 2}$ & S1 & $\mathbf{S 2}$ & S1 & $\mathbf{S 2}$ \\
\hline \multicolumn{7}{|l|}{ SHAM } \\
\hline Saline & $53.3 \pm 13.6$ & $22.9 \pm 5.7^{\#}$ & $35.2 \pm 10.4$ & $15.2 \pm 5.7^{\#}$ & $-20.2 \pm 8.2$ & $-7.7 \pm 4.0^{\#}$ \\
\hline Apomorphine & $38.8 \pm 10.5^{*}$ & $21.9 \pm 5.7^{\#}$ & $11.8 \pm 2.8^{*}$ & $7.4 \pm 2.5^{\#}$ & $-27.0 \pm 11.4$ & $-14.5 \pm 6.4^{\#}$ \\
\hline Amphetamine & $18.6 \pm 3.3^{*}$ & $16.5 \pm 2.4^{\#}$ & $10.1 \pm 2.9^{*}$ & $13.0 \pm 4.7$ & $-8.5 \pm 4.5^{*}$ & $-3.4 \pm 3.4$ \\
\hline MK-801 & $33.2 \pm 6.4^{*}$ & $23.6 \pm 3.4^{\#}$ & $20.7 \pm 3.4^{*}$ & $20.8 \pm 4.6$ & $-12.5 \pm 7.5^{*}$ & $-2.8 \pm 4.1$ \\
\hline \multicolumn{7}{|l|}{ CAST } \\
\hline Saline & $82.7 \pm 15.6$ & $35.3 \pm 8.2^{\#}$ & $45.3 \pm 13.3$ & $18.5 \pm 8.7^{\#}$ & $-37.4 \pm 14.7$ & $-16.8 \pm 8.6^{\#}$ \\
\hline Apomorphine & $54.8 \pm 13.4^{*}$ & $34.4 \pm 8.1^{\#}$ & $34.5 \pm 11.8^{*}$ & $21.8 \pm 5.9^{\#}$ & $-20.3 \pm 8.8$ & $-12.6 \pm 4.7^{\#}$ \\
\hline Amphetamine & $28.4 \pm 5.7^{*}$ & $20.5 \pm 3.1^{\#}$ & $18.4 \pm 4.0^{*}$ & $15.8 \pm 3.0$ & $-10.1 \pm 4.2 *$ & $-4.7 \pm 4.3$ \\
\hline MK-801 & $34.0 \pm 8.4^{*}$ & $21.4 \pm 3.1^{\#}$ & $21.3 \pm 5.7^{*}$ & $15.2 \pm 4.7$ & $-12.7 \pm 7.6^{*}$ & $-6.2 \pm 4.5$ \\
\hline \multicolumn{7}{|l|}{ CAST+DHT } \\
\hline Saline & $64.6 \pm 12.8$ & $31.3 \pm 8.8^{\#}$ & $43.0 \pm 10.6$ & $20.5 \pm 5.9^{\#}$ & $-21.6 \pm 6.0$ & $-10.7 \pm 6.1^{\#}$ \\
\hline Apomorphine & $53.5 \pm 8.6^{*}$ & $34.8 \pm 7.1^{\#}$ & $35.3 \pm 9.4^{*}$ & $23.9 \pm 5.4^{\#}$ & $-18.3 \pm 7.3$ & $-10.9 \pm 4.1^{\#}$ \\
\hline Amphetamine & $34.8 \pm 9.2^{*}$ & $22.1 \pm 5.1^{\#}$ & $23.4 \pm 7.2^{*}$ & $16.9 \pm 8.0$ & $-11.5 \pm 4.3^{*}$ & $-5.2 \pm 3.9$ \\
\hline MK-801 & $32.8 \pm 6.4^{*}$ & $30.5 \pm 4.2^{\#}$ & $29.1 \pm 6.1^{*}$ & $25.6 \pm 4.2$ & $-3.8 \pm 6.7^{*}$ & $-4.9 \pm 5.2$ \\
\hline
\end{tabular}


* $\mathrm{P}<0.05$ compared to saline treatment

${ }^{\#} \mathrm{P}<0.05$ compared to $\mathrm{S} 1$. 


\section{FIGURE LEGENDS}

SHAM

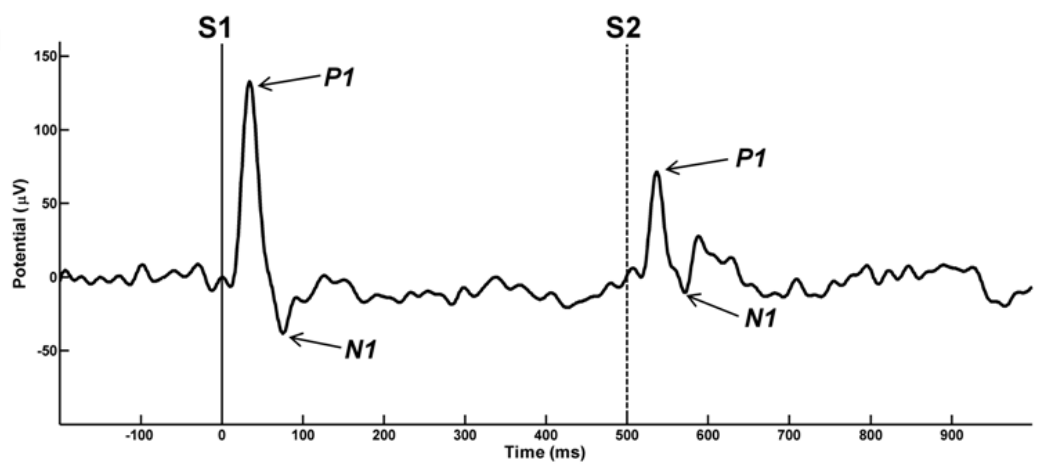

ovx

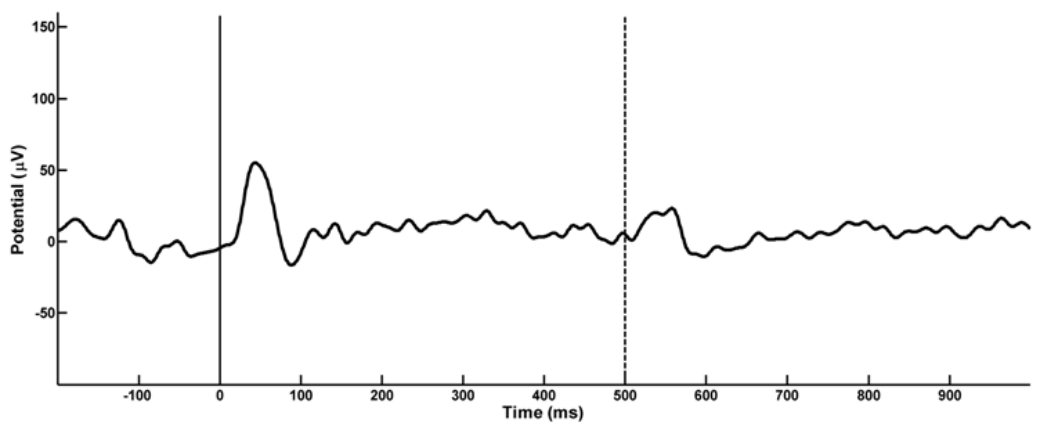

$O V X+E$

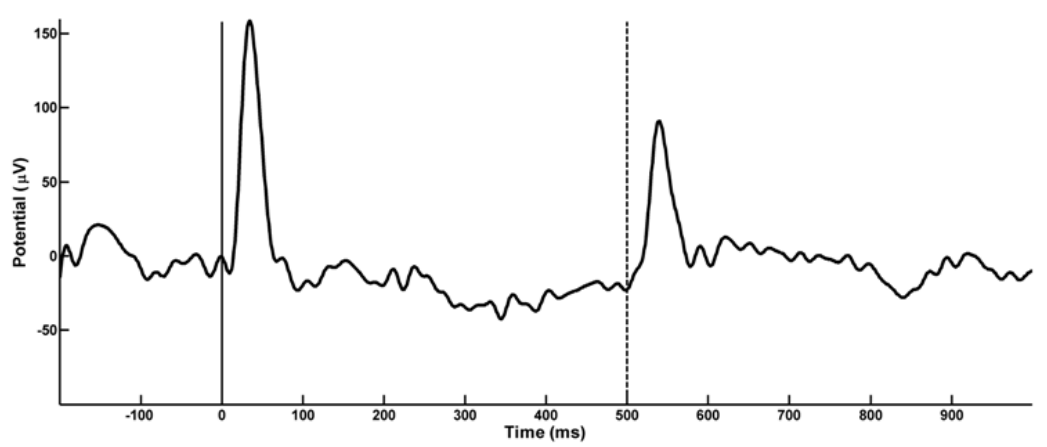

Figure 1

Typical traces of event-related potentials after administration of saline. Rats were either sham-operated (SHAM), ovariectomized (OVX) or ovariectomized and implanted with $17 \beta$-estradiol $(\mathrm{OVX}+\mathrm{E}) . \mathrm{S} 1$ and $\mathrm{S} 2$ occurred at $0 \mathrm{~ms}$ and $500 \mathrm{~ms}$ respectively. P1 and N1 components are indicated in the top panel. 
a)

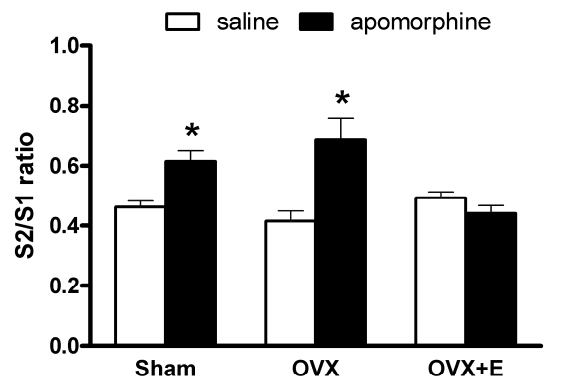

b)
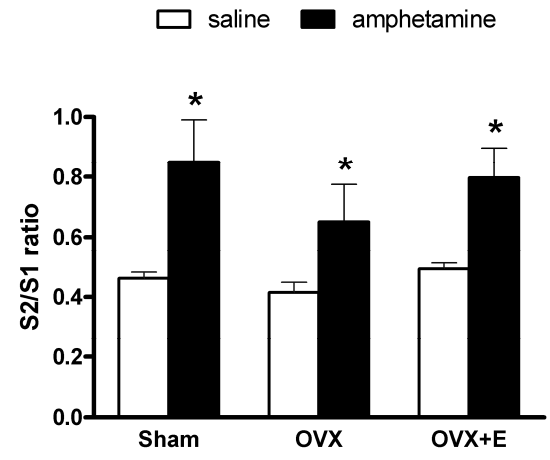

c)

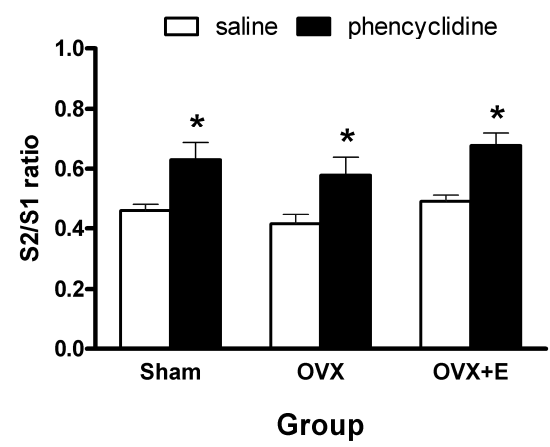

Figure 2

Mean ( \pm S.E.M.) S2/S1 ratios following administration of saline or a) $0.1 \mathrm{mg} / \mathrm{kg}$ apomorphine, b) $0.5 \mathrm{mg} / \mathrm{kg}$ amphetamine or c) $2.5 \mathrm{mg} / \mathrm{kg}$ phencyclidine, in rats that were either sham-operated (SHAM), ovariectomized (OVX) or ovariectomized and implanted with $17 \beta$-estradiol $(\mathrm{OVX}+\mathrm{E} ; n=8$ per group). Identical bars for saline in each graph reflect the repeated measures design. 

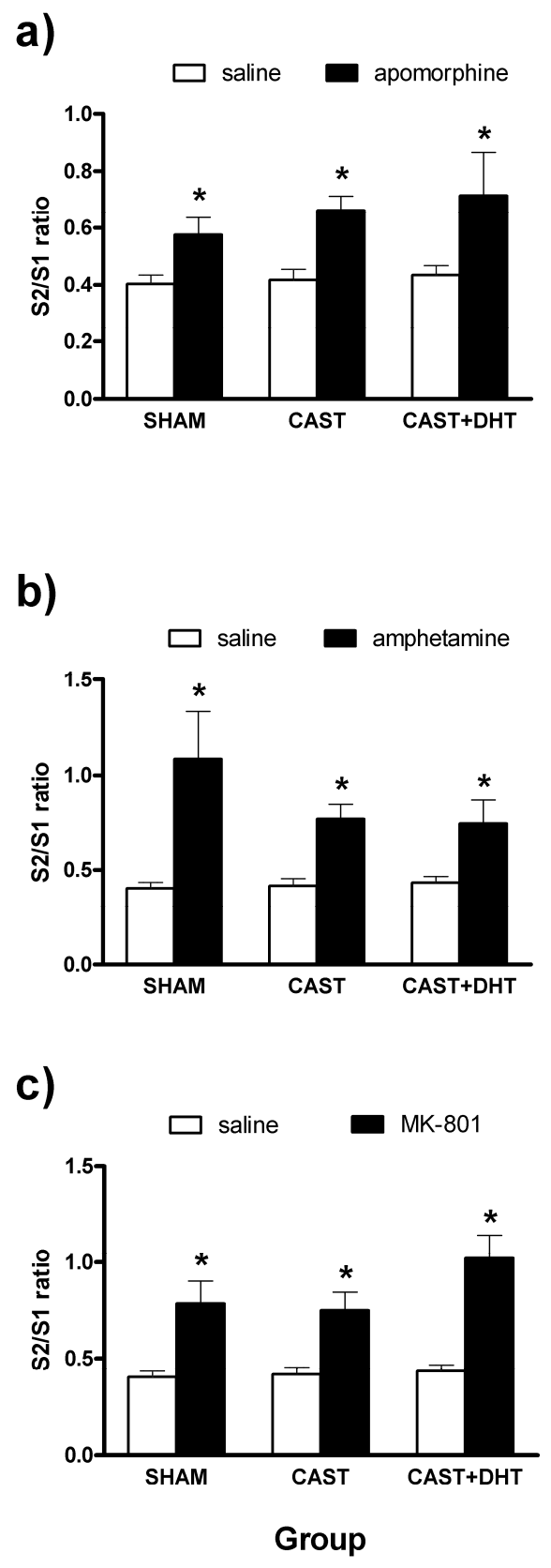

Figure 3

Mean ( \pm S.E.M.) S2/S1 ratios following administration of saline or a) $0.1 \mathrm{mg} / \mathrm{kg}$ apomorphine, b) $0.5 \mathrm{mg} / \mathrm{kg}$ amphetamine or c) $0.05 \mathrm{mg} / \mathrm{kg} \mathrm{MK}-801$, in male rats that were either sham-operated (SHAM), castrated (CAST) or castrated and implanted with dihydrotestosterone (CAST+DHT; $n=8$ per group). Identical bars for saline in each graph reflect the repeated measures design. 


\section{REFERENCES}

Adler LE, Pachtman E, Franks RD, Pecevich M, Waldo MC, Freedman R (1982) Neurophysiological evidence for a defect in neuronal mechanisms involved in sensory gating in schizophrenia. Biol Psychiatry 17: 639-54.

Adler LE, Pang K, Gerhardt G, Rose GM (1988) Modulation of the gating of auditory evoked potentials by norepinephrine: pharmacological evidence obtained using a selective neurotoxin. Biol Psychiatry 24: 179-90.

Adler LE, Rose G, Freedman R (1986) Neurophysiological studies of sensory gating in rats: effects of amphetamine, phencyclidine, and haloperidol. Biol Psychiatry 21: 787-98.

Albert DJ, Jonik RH, Gorzalka BB, Newlove T, Webb B, Walsh ML (1991) Serum estradiol concentration required to maintain body weight, attractivity, proceptivity, and receptivity in the ovariectomized female rat. Physiology and Behavior 49: 225-31.

Bayer TA, Falkai P, Maier W (1999) Genetic and non-genetic vulnerability factors in schizophrenia: the basis of the "two hit hypothesis". J Psychiatr Res 33: 5438 .

Becker J, Gomes I, Ghisolfi ES, Schuch A, Ramos FLP, Ehlers JA, Nora DB, Lara DR, da Costa JC (2004) Clozapine, but not typical antipsychotics, correct P50 suppression deficit in patients with schizophrenia. Clin Neurophysiol 115: 396-401.

Bickford-Wimer PC, Nagamoto H, Johnson R, Adler LE, Egan M, Rose GM, Freedman R (1990) Auditory sensory gating in hippocampal neurons: a model system in the rat. Biol Psychiatry 27: 183-92.

Bisagno V, Ferguson D, Luine VN (2003) Chronic D-amphetamine induces sexually dimorphic effects on locomotion, recognition memory, and brain monoamines. Pharmacology Biochemistry and Behavior 74: 859-67.

Boutros NN, Bonnet KA, Millana R, Liu J (1997) A parametric study of the N40 auditory evoked response in rats. Biol Psychiatry 42: 1051-1059.

Boutros NN, Brockhaus-Dumke A, Gjini K, Vedeniapin A, Elfakhani M, Burroughs S, Keshavan M (2009) Sensory-gating deficit of the N100 mid-latency auditory evoked potential in medicated schizophrenia patients. Schizophr Res 113: 339-46.

Breier MR, Lewis B, Shoemaker JM, Light GA, Swerdlow NR (2010) Sensory and sensorimotor gating-disruptive effects of apomorphine in Sprague Dawley and Long Evans rats. Behavioral Brain Research 208: 560-5.

Brenner CA, Edwards CR, Carroll CA, Kieffaber PD, Hetrick WP (2004) P50 and acoustic startle gating are not related in healthy participants. Psychophysiology 41: 702-708. 
Cadenhead KS, Light GA, Shafer KM, Braff DL (2005) P50 suppression in individuals at risk for schizophrenia: The convergence of clinical, familial, and vulnerability marker risk assessment. Biol Psychiatry 57: 1504-1509.

Carlsson A, Waters N, Carlsson ML (1999) Neurotransmitter interactions in schizophrenia--therapeutic implications. Biol Psychiatry 46: 1388-95.

Carlsson A, Waters N, Holm-Waters S, Tedroff J, Nilsson M, Carlsson ML (2001) Interactions between monoamines, glutamate, and GABA in schizophrenia: new evidence. Annual Review of Pharmacology and Toxicology 41: 237-60.

Chavez C, Hollaus M, Scarr E, Pavey G, Gogos A, van den Buuse M (2010) The effect of estrogen on dopamine and serotonin receptor and transporter levels in the brain: an autoradiography study. Brain Res 1321: 51-9.

Choy KH, de Visser YP, van den Buuse M (2009) The effect of 'two hit' neonatal and young-adult stress on dopaminergic modulation of prepulse inhibition and dopamine receptor density. Br J Pharmacol 156: 388-96.

Chua W, de Izquierdo Santiago A, Kulkarni J, Mortimer A (2004) Oestrogen for schizophrenia (Protocol) The Cochrane Database of Systematic Reviews, Issue 1, 2004.

Dalecki A, Croft RJ, Johnstone SJ (2011) An evaluation of P50 paired-click methodologies. Psychophysiology 48: 1692-1700.

Delorme A, Makeig S (2004) EEGLAB: an open source toolbox for analysis of single-trial EEG dynamics including independent component analysis. Journal of Neuroscience Methods 134: 9-21.

Di Paolo T (1994) Modulation of brain dopamine transmission by sex steroids. Reviews in Neuroscience 5: 27-41.

Dissanayake DW, Zachariou M, Marsden CA, Mason R (2009) Effects of phencyclidine on auditory gating in the rat hippocampus and the medial prefrontal cortex. Brain Res 1298: 153-60.

Garcia-Segura LM, Azcoitia I, DonCarlos LL (2001) Neuroprotection by estradiol. Progress in Neurobiology 63: 29-60.

Gogos A, Kwek P, Chavez C, van den Buuse M (2010) Estrogen treatment blocks 8-hydroxy-2-dipropylaminotetralin- and apomorphine-induced disruptions of prepulse inhibition: involvement of dopamine D1 or D2 or serotonin 5-HT1A, 5-HT2A, or 5-HT7 receptors. Journal of Pharmacology and Experimental Therapeutics 333: 218-27.

Gogos A, Kwek P, van den Buuse M (2011) The role of estrogen and testosterone in female rats in behavioral models of relevance to schizophrenia. Psychopharmacology (Berl) 219: 213-24. 
Gogos A, van den Buuse M (2003) Castration reduces the effect of serotonin-1A receptor stimulation on prepulse inhibition in rats. Behavioral Neuroscience 117: $1407-15$.

Gogos A, Van den Buuse M (2004) Estrogen and progesterone prevent disruption of prepulse inhibition by the serotonin-1A receptor agonist 8-hydroxy-2dipropylaminotetralin. Journal of Pharmacology and Experimental Therapeutics 309: 267-74.

Hafner H (2003) Gender differences in schizophrenia. Psychoneuroendocrinology 28 Suppl 2: 17-54.

Jansen BH, Hu L, Boutros NN (2010) Auditory evoked potential variability in healthy and schizophrenia subjects. Clin Neurophysiol 121: 1233-9.

Keedy SK, Marlow-O'Connor M, Beenken B, Dorflinger J, Abel M, Erwin RJ (2007) Noradrenergic antagonism of the P13 and N40 components of the rat auditory evoked potential. Psychopharmacology (Berl) 190: 117-25.

Kokkinidis L, Anisman H (1980) Amphetamine models of paranoid schizophrenia: an overview and elaboration of animal experimentation. Psychology Bulletin 88: 551-79.

Kulkarni J, Riedel A, de Castella AR, Fitzgerald PB, Rolfe TJ, Taffe J, Burger H (2001) Estrogen - a potential treatment for schizophrenia. Schizophr Res 48: $137-44$.

Light GA, Braff DL (1999) Human and animal studies of schizophrenia-related gating deficits. Current Psychiatry Reports 1: 31-40.

Light GA, Geyer MA, Clementz BA, Cadenhead KS, Braff DL (2000) Normal P50 suppression in schizophrenia treated with atypical antipsychotic medications. Am J Psychiat 157: 767-771.

Light GA, Williams LE, Minow F, Sprock J, Rissling A, Sharp R, Swerdlow NR, Braff DL (2010) Electroencephalography (EEG) and event-related potentials (ERPs) with human participants. Current Protocols in Neuroscience Chapter 6: Unit 625 1-24.

McGrath J, Saha S, Chant D, Welham J (2008) Schizophrenia: a concise overview of incidence, prevalence, and mortality. Epidemiol Rev 30: 67-76.

Morris BJ, Cochran SM, Pratt JA (2005) PCP: from pharmacology to modelling schizophrenia. Current Opinions in Pharmacology 5: 101-6.

Oades RD, Schepker R (1994) Serum gonadal steroid hormones in young schizophrenic patients. Psychoneuroendocrinology 19: 373-85.

Olincy A, Braff DL, Adler LE, Cadenhead KS, Calkins ME, Dobie DJ, Green MF, Greenwood TA, Gur RE, Gur RC, Light GA, Mintz J, Nuechterlein KH, Radant AD, Schork NJ, Seidman LJ, Siever LJ, Silverman JM, Stone WS, Swerdlow NR, Tsuang DW, Tsuang MT, Turetsky BI, Wagner BD, 
Freedman R (2010) Inhibition of the P50 cerebral evoked response to repeated auditory stimuli: results from the Consortium on Genetics of Schizophrenia. Schizophr Res 119: 175-82.

Oranje B, Aggernaes B, Rasmussen H, Ebdrup BH, Glenthøj BY (2013) P50 suppression and its neural generators in antipsychotic-Naïve first-episode schizophrenia before and after 6 months of quetiapine treatment. Schizophrenia Bulletin 39: 472-480.

Patterson JV, Hetrick WP, Boutros NN, Jin Y, Sandman C, Stern H, Potkin S, Bunney WE (2008) P50 sensory gating ratios in schizophrenics and controls: A review and data analysis. Psychiatry Res 158: 226-247.

Riecher-Rossler A, Hafner H, Stumbaum M, Maurer K, Schmidt R (1994) Can estradiol modulate schizophrenic symptomatology? Schizophrenia Bulletin 20: $203-14$

SANE (2002) Schizophrenia: Costs. An analysis of the burden of schizophrenia and related suicide in Australia. An access economics report for SANE Australia 2002.

Schank JC (2001) Do Norway rats (Rattus norvegicus) synchronize their estrous cycles? Physiology and Behavior 72: 129-39.

Simpson J, Kelly JP (2012) An investigation of whether there are sex differences in certain behavioural and neurochemical parameters in the rat. Behavioral Brain Research 229: 289-300.

Stevens KE, Fuller LL, Rose GM (1991) Dopaminergic and noradrenergic modulation of amphetamine-induced changes in auditory gating. Brain Res 555: 91-8.

Svenningsson P, Tzavara ET, Carruthers R, Rachleff I, Wattler S, Nehls M, McKinzie DL, Fienberg AA, Nomikos GG, Greengard P (2003) Diverse psychotomimetics act through a common signaling pathway. Science 302: 1412-5.

Swerdlow NR, Geyer MA, Shoemaker JM, Light GA, Braff DL, Stevens KE, Sharp R, Breier M, Neary A, Auerbach PP (2006) Convergence and divergence in the neurochemical regulation of prepulse inhibition of startle and N40 suppression in rats. Neuropsychopharmacology 31: 506-15.

Venables PH (1964) Input Dysfunction in Schizophrenia. Progress in experimental personality research $72: 1-47$.

Waldo MC, Graze K, Bender SdG, Adler LE, Freedman R (1987) Premenstrual mood changes and gating of the auditory evoked potential. Psychoneuroendocrinology 12: 35-40. 